\title{
Selected thermal properties of polyethylene waxes
}

\author{
Wiesława Ciesińska ${ }^{1} \cdot$ Barbara Liszyńska $^{1} \cdot$ Janusz Zieliński $^{1}$
}

Received: 15 November 2015 / Accepted: 12 July 2016/Published online: 25 July 2016

(c) The Author(s) 2016. This article is published with open access at Springerlink.com

\begin{abstract}
Selected thermal properties of different types of polyethylene waxes, i.e. by-products formed in ethylene low-pressure polymerization process, physically and chemically modified waxes are presented in the study. Temperatures of phase transitions and relevant thermal effects were defined using DSC method. Additionally, drop point and penetration of waxes were determined. It was established that fractionation of waxes (physical modification) causes increase in their crystallinity and oxidation (chemical modification) decreases ability for crystallization.
\end{abstract}

Keywords Polyethylene waxes · Modification · Thermal properties · DSC

\section{Introduction}

Dynamic development of polyolefin production in synthesis process is associated with forming of by-products of waxy nature, which requires management.

Synthetic polyethylene waxes being the ethylene oligomers of mean molecular mass below $10,000 \mathrm{~g} \mathrm{~mol}^{-1}$ are the example of that type of products. They are formed as by-product in ethylene polymerization processes. As their accumulation in reaction system is unfavourable, they must be removed from reactor systems. Ethylene polymerization using suspension method is the typical example [1]. Polyolefin waxes can also be produced in direct synthesis from

Wiesława Ciesińska

w.ciesinska@pw.plock.pl

1 Faculty of Civil Engineering, Mechanics and Petrochemistry, Institute of Chemistry, Warsaw University of Technology, Lukasiewicza 17, 09-400 Plock, Poland olefins and thermal degradation of polyolefins or their wastes [2, 3].

Different plastic grades are produced in industrial ethylene polymerization plants, which vary in density, melt flow rate, usable properties and applications, among other things. It is possible thanks to change in adequate process parameters such as type of catalyst, amount of hydrogen, amount of co-monomer (density regulator). Change in above parameters can also affect the properties of polyethylene wax produced in the process [4].

Introduction of polyethylene waxes on the market opened a series of new applications for that type of products and also caused the necessity of detailed recognition of their properties.

Polyethylene waxes can be used in many applications, e.g. in cabling and electrotechnical industry, rubber industry, PVC processing, for production of dye concentrates, printer's inks, in lacquer and textile industry, for bitumen and paraffin modification, hydrophobic treatment of wooden surfaces, in production of fertilizers [5-8]. The possibility of wax use is determined by its thermal properties, among other things. Recognition of these properties enables proper processing of waxes, shows the needs of modification and opens new directions of use.

Wax properties can be modified using both physical methods (e.g. by fractionation) and chemical ones. Oxidation of waxes is one of the methods of wax chemical modification, which enables formation of polar waxes used for the production of waxy microemulsions. Application of waxes in emulsion form assures easy use without the need of heating and melting and also eliminates the necessity of use of organic solvents [9].

Differential scanning calorimetry (DSC) is one of the methods which enable determination of thermal properties of waxes. 
In this work, the thermal properties of polyethylene waxes were determined. Examined waxes had different process parameters of polyethylene synthesis as well as the modification method and ratio.

\section{Experimental}

Examinations were conducted for three groups of polyethylene waxes (Table 1):

- by-products formed in low-pressure suspension polymerization of ethylene during production of three types of polyethylene intended for injection moulding (unmodified wax A), film production (unmodified wax B), blowing extrusion (unmodified wax $\mathrm{C}$ ), produced in Basell Orlen Polyolefins Sp. z o.o. in Plock (Poland);

- polyethylene waxes physically modified using fractionation and granulation methods, varied in hardness value (fractionated waxes D-G), between other things, produced in Wiwax Sp. z o.o. in Plock (Poland);

- chemically modified polyethylene waxes by oxidation with air in melted condition, without addition of initiating agents, formed at different amount of added air (oxidized waxes I-M). Oxidation was run in temperature $433 \mathrm{~K}$, during $5 \mathrm{~h}$. Fractionated wax $\mathrm{H}^{*}$, according to designation in this document, was used as raw material for oxidation process. Oxidizing agent, i.e. air, was introduced to melted wax through capillary tube under flow control. Reactor content was mixed with rotational speed of $100 \mathrm{rpm}$ during oxidation. Mass of used raw material was $150 \mathrm{~g}$. Advancement of reaction was determined by acid number.
DSC measurements were performed by means of Netzsch model 200F3 Maia instrument, in atmosphere of nitrogen. The measurement procedure involved initial heating of the sample to $423 \mathrm{~K}$, cooling to the temperature of $243 \mathrm{~K}$ and reheating to $423 \mathrm{~K}$. The rate of heating/cooling of the sample was $20 \mathrm{~K} \mathrm{~min}^{-1}$. Melting and crystallization temperatures $\left(T_{\mathrm{m}}, T_{\mathrm{c}}\right)$, and enthalpy of these transitions $\left(\Delta H_{\mathrm{m}}, \Delta H_{\mathrm{c}}\right)$ were read out from DSC curves. Making use of melting enthalpy value, the wax crystallinity was defined on the basis of formula [10]:

$X_{\mathrm{c}}=\frac{\Delta H_{\mathrm{m}}}{\Delta H_{\mathrm{m}}^{0}} \times 100$

where $X_{\mathrm{c}} / \%$, crystallinity, $\Delta H_{\mathrm{m}} / \mathrm{J} \mathrm{g}^{-1}$, wax melting enthalpy, $\Delta H_{\mathrm{m}}^{0} / \mathrm{J} \mathrm{g}^{-1}$, melting enthalpy of $100 \%$ crystalline polyethylene $\left(277 \mathrm{~J} \mathrm{~g}^{-1}\right)$.

Typical determinations for examined waxes were additionally performed:

- drop point using Ubbelohde method;

- penetration according to PN-C-04161:1982;

- acid number according to ASTM D 1386-98.

\section{Results}

Physical and chemical properties of polyethylene waxes are presented in Table 1; thermal characteristic of polyethylene waxes read out from curves obtained by DSC method is shown in Table 2.

Waxes being the by-products formed in low-pressure suspension polymerization of ethylene during production of different types of polyethylene had different thermal

Table 1 Physical and chemical properties of polyethylene waxes

\begin{tabular}{|c|c|c|c|c|}
\hline Wax symbol & Air flow/dm ${ }^{3} h^{-1}$ & Acid number/mg g ${ }^{-1}$ & Drop point/K & Penetration $(298 \mathrm{~K}) / 0.1 \mathrm{~mm}$ \\
\hline Unmodified wax A & - & 0.00 & 366 & 31 \\
\hline Unmodified wax B & - & 0.00 & 368 & 33 \\
\hline Unmodified wax $\mathrm{C}$ & - & 0.00 & 380 & 23 \\
\hline Fractionated wax D & - & 0.00 & 380 & 25 \\
\hline Fractionated wax E & - & 0.00 & 383 & 15 \\
\hline Fractionated wax F & - & 0.00 & 385 & 5 \\
\hline Fractionated wax $G$ & - & 0.00 & 387 & 2 \\
\hline Fractionated wax $\mathrm{H}^{*}$ & - & 0.00 & 380 & 7 \\
\hline Oxidized wax I & 100 & 3.61 & 377 & 8 \\
\hline Oxidized wax J & 125 & 4.89 & 375 & 8 \\
\hline Oxidized wax $\mathrm{K}$ & 150 & 5.39 & 373 & 8 \\
\hline Oxidized wax L & 175 & 8.56 & 372 & 9 \\
\hline Oxidized wax $\mathrm{M}$ & 200 & 11.54 & 367 & 10 \\
\hline
\end{tabular}

* Raw material for oxidation 
Table 2 Thermal properties of polyethylene waxes

\begin{tabular}{|c|c|c|c|c|c|c|c|c|}
\hline \multirow[t]{2}{*}{ Wax symbol } & \multicolumn{4}{|c|}{ Melting } & \multicolumn{3}{|c|}{ Crystallization } & \multirow[t]{2}{*}{ Crystallinity $X_{\mathrm{c}} / \%$} \\
\hline & $\overline{T_{\mathrm{m} 1} / \mathrm{K}}$ & $T_{\mathrm{m} 2} / \mathrm{K}$ & $T_{\mathrm{m} 3} / \mathrm{K}$ & $\Delta H_{\mathrm{m}} / \mathrm{J} \mathrm{g}^{-1}$ & $T_{\mathrm{cl} 1} / \mathrm{K}$ & $T_{\mathrm{c} 2} / \mathrm{K}$ & $\Delta H_{\mathrm{c}} / \mathrm{J} \mathrm{g}^{-1}$ & \\
\hline Unmodified wax A & 349.7 & - & - & 124.3 & 337.5 & - & 124.4 & 44.9 \\
\hline Unmodified wax B & 341.1 & 359.7 & 369.5 & 96.6 & 330.7 & 354.6 & 93.1 & 34.9 \\
\hline Unmodified wax $\mathrm{C}$ & 353.2 & 366.8 & - & 109.4 & 340.9 & 356.8 & 101.4 & 39.5 \\
\hline Fractionated wax D & 343.1 & 360.5 & 384.0 & 181.1 & 357.0 & 332.8 & 180.9 & 65.4 \\
\hline Fractionated wax E & 344.4 & 361.7 & 371.5 & 190.3 & 359.0 & 335.5 & 188.8 & 68.7 \\
\hline Fractionated wax F & - & 371.9 & 381.6 & 217.7 & 359.1 & - & 217.8 & 78.6 \\
\hline Fractionated wax $G$ & - & 373.8 & 388.2 & 200.3 & 371.6 & 354.4 & 200.7 & 72.3 \\
\hline Fractionated wax $\mathrm{H}^{*}$ & - & 371.9 & 381.6 & 217.7 & - & 359.1 & 217.8 & 78.6 \\
\hline Oxidized wax I & 364.1 & 369.7 & 379.4 & 198.1 & - & 353.4 & 202.4 & 71.5 \\
\hline Oxidized wax J & 363.4 & 368.1 & - & 196.1 & - & 352.3 & 196.4 & 70.8 \\
\hline Oxidized wax $\mathrm{K}$ & 362.9 & - & - & 195.3 & - & 352.0 & 195.5 & 70.5 \\
\hline Oxidized wax L & 361.6 & - & - & 180.8 & - & 349.9 & 181.6 & 65.3 \\
\hline Oxidized wax M & 359.9 & - & - & 175.8 & - & 348.1 & 180.2 & 63.5 \\
\hline
\end{tabular}

* Raw material for oxidation

properties. The highest thermal resistance was shown by wax formed in production process of polyethylene intended for blowing extrusion. It was indicated by values of drop point and penetration temperatures (Table 1) and phase transition temperatures (Table 2).

Run of DSC curves presented in Figs. 1 and 2 shows differences in course of melting and crystallization of waxes obtained at different parameters of polymerization process. However, the presence of two or three peaks was observed for waxes originating from synthesis of multimodal grades, which suggests a broad molecular weight distribution. It was also noticed that wax formed during production of film grade was characterized by lowest content of crystal phase. It probably resulted from use of highest amount of butene-1 (density regulator) during

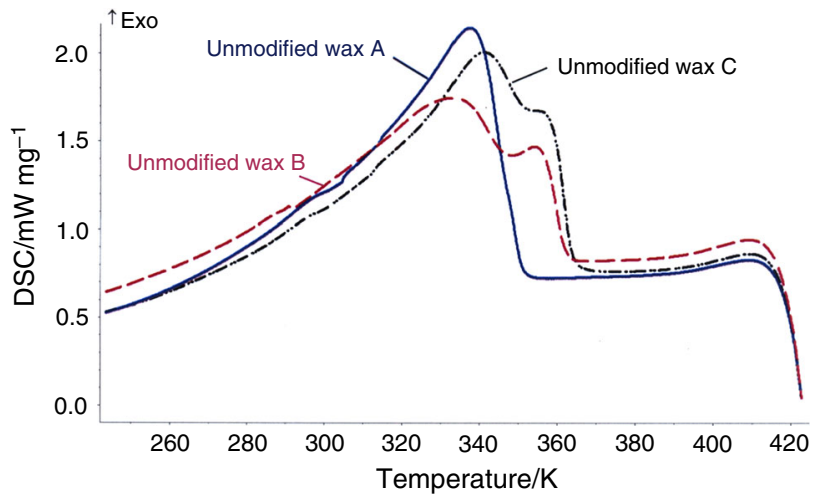

Fig. 1 Cooling-stage DSC curve of polyethylene waxes formed during production of high-density polyethylene varying in applications: injection moulding-unmodified wax A, film productionunmodified wax B, blowing extrusion-unmodified wax C

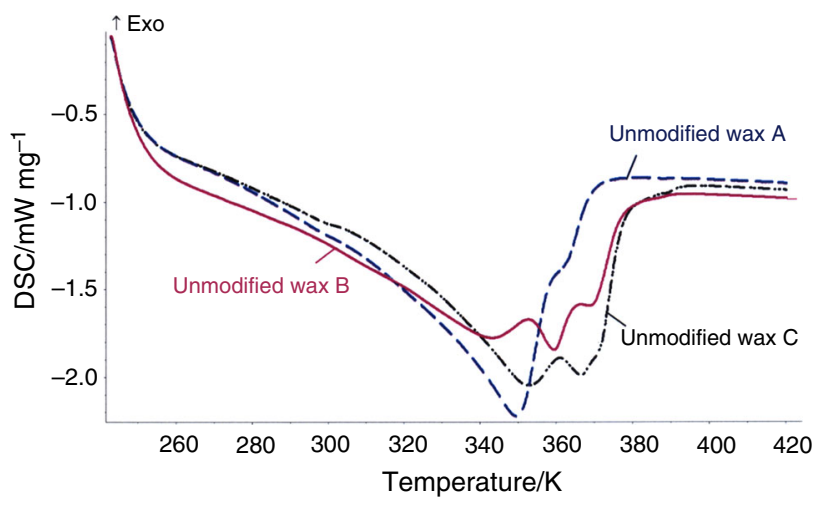

Fig. 2 Reheating-stage DSC curve of polyethylene waxes formed during production of high-density polyethylene varying in applications: injection moulding-unmodified wax A, film productionunmodified wax $\mathrm{B}$, blowing extrusion-unmodified wax $\mathrm{C}$

production of that grade. Addition of butene-1 influences the length of side branches, and therefore, it decreases wax ability for crystallization.

Formation of products which vary in penetration value and thereby in hardness (Table 1) was the purpose of modification. It was achieved by fractionation consisting in removal—in different extent-of low-molecular products containing up to 14 atoms of carbon in molecule.

The presence of exothermic process (two characteristic peaks and one for fractionated wax F) as crystallization effect of waxes (Fig. 3) was found on DSC curves for cooling stage. Readout temperatures were increasing when wax penetration was decreasing (Table 2). Similarly, endothermic transition (three characteristic peaks and two peaks for fractionated waxes $\mathrm{F}$ and $\mathrm{G}$ ) as the melting result 


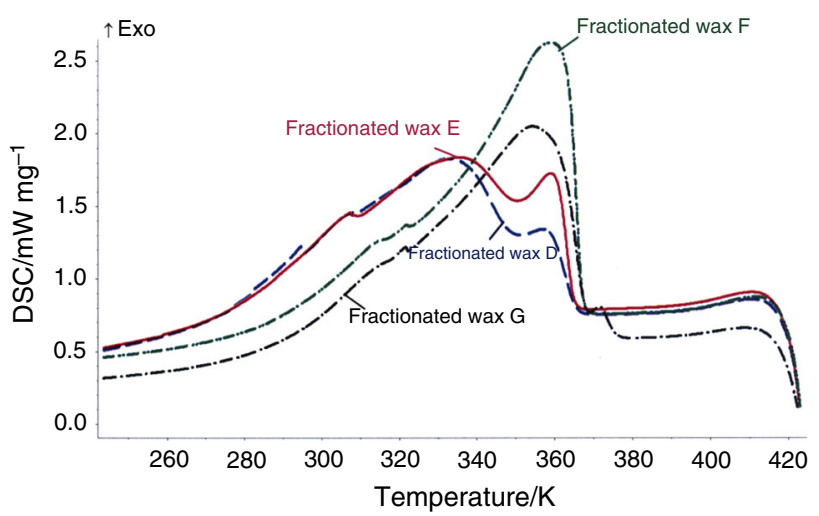

Fig. 3 Cooling-stage DSC curve of physically modified polyethylene waxes: fractionated wax $\mathrm{D}$, fractionated wax $\mathrm{E}$, fractionated wax $\mathrm{F}$, fractionated wax $\mathrm{G}$

was present in reheating stage (Fig. 4). By analogy, readout temperature values were increasing when sample penetration was decreasing. The presence of two characteristic peaks instead of one on curves points out at existence in waxes of fractions which differ in molecular weight. Absolute values of energetic effects of transitions were practically equal and also were increasing together with increase in wax hardness (except from fractionated wax G). It indicates that decrease in low-molecular compound content on waxes increases their ability to crystallization.

Chemically modified waxes varied in oxidation state measured by the value of acid number. In comparison to initial wax, oxidation waxes characterized by lowered drop point and decreasing hardness, proportionally to oxidation state (Table 1). Changes in properties caused by oxidation were also seen on DSC curves (Figs. 5, 6; Table 2). Crystallization and melting temperatures were lower in

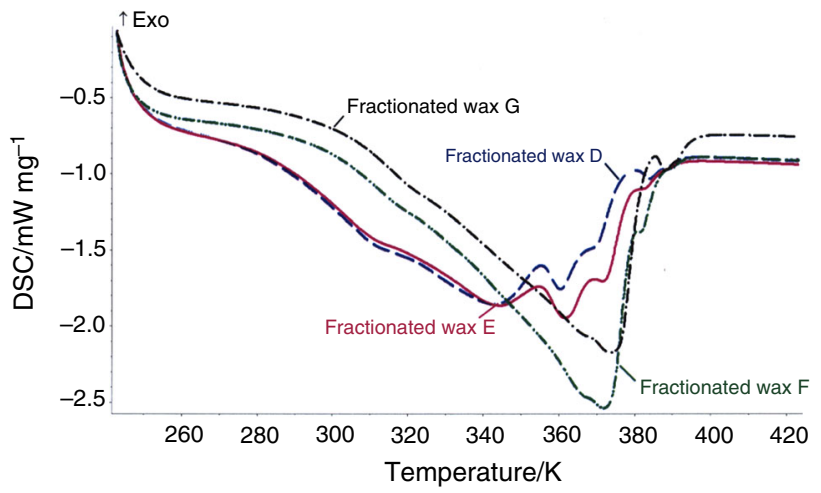

Fig. 4 Reheating-stage DSC curve of physically modified polyethylene waxes: fractionated wax $\mathrm{D}$, fractionated wax $\mathrm{E}$, fractionated wax $F$, fractionated wax $G$

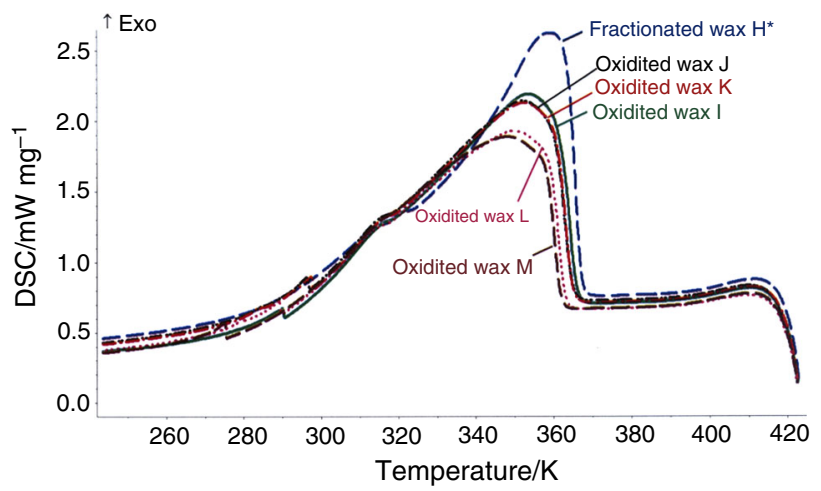

Fig. 5 Cooling-stage DSC curve of chemically modified polyethylene waxes: fractionated wax $\mathrm{H}^{*}$-raw material for oxidation, oxidized wax I, oxidized wax $\mathrm{J}$, oxidized wax $\mathrm{K}$, oxidized wax $\mathrm{L}$, oxidized wax $\mathrm{M}$

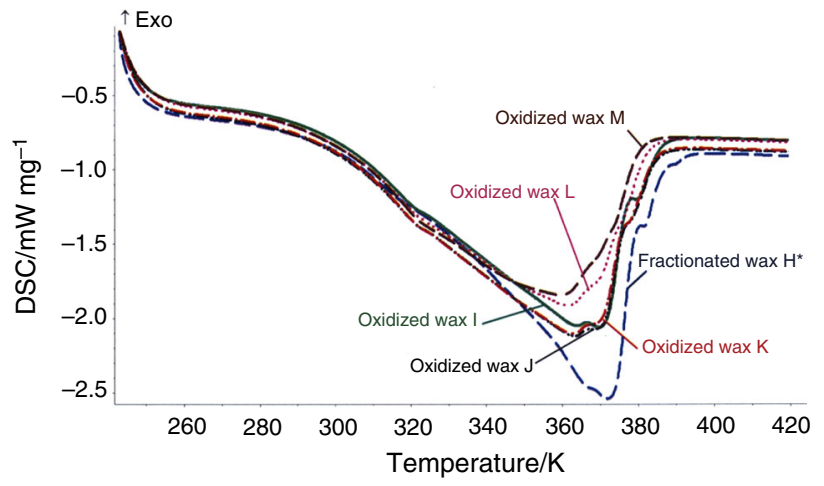

Fig. 6 Reheating-stage DSC curve of chemically modified polyethylene waxes: fractionated wax $\mathrm{H}$-raw material for oxidation, oxidized wax I, oxidized wax $\mathrm{J}$, oxidized wax $\mathrm{K}$, oxidized wax $\mathrm{L}$, oxidized wax $\mathrm{M}$

comparison with initial fractionated wax $\mathrm{H}$ and were decreasing together with increase in oxidation state. Absolute values of energetic effects of these transitions were analogically arranged. It showed that introduction of oxygen functional groups decreased ability of waxes to crystallization. It was proved by calculated content of crystal phase (Table 2) which was decreasing when oxidation state was increasing. Absolute values of crystallization and melting energetic effects were practically equal. Few melting peaks were present in reheating stage for initial fractionated wax $\mathrm{H}$ and for waxes of lower oxidation state. It suggested the presence of fractions which varied in molecular weight. That effect was not observed in case of waxes of higher oxidation state, which most probably resulted from degradation associated with oxidation. 


\section{Conclusions}

Impact of modification method of polyethylene waxes on their properties was demonstrated. Waxes formed as byproducts during production of high-density polyethylene by suspension method had the highest penetration value, i.e. the lowest hardness in comparison with waxes modified both physically and chemically. Most of examined waxes contained fractions of different molecular weight, two or three peaks on melting and crystallization curves. Physical modification of waxes by removal of fractions of lowest molecular weights led to increase in the content of crystal phase. In case of chemical modification, increase in oxidation state led to decrease in ability to crystallization due to introduction of groups which make crystallization more difficult. It was demonstrated that the products of assumed properties, intended for specific applications, can be formed by modification of polyethylene waxes. Physical modification of waxes enabled increase in their thermal resistance. Introduction of hydrophilic functional groups to waxes, e.g. by their oxidation, enables production of stable emulsions from that type of compound, which considerably simplifies application of waxes by eliminating the necessity of their melting or using solvents.

Open Access This article is distributed under the terms of the Creative Commons Attribution 4.0 International License (http://crea tivecommons.org/licenses/by/4.0/), which permits unrestricted use, distribution, and reproduction in any medium, provided you give appropriate credit to the original author(s) and the source, provide a link to the Creative Commons license, and indicate if changes were made.

\section{References}

1. Marszałek G, Zieliński J, Ciesińska W. Production of the polyethylene wax by high and low pressure polymerization. Przem Chemiczny. 2011;90:1264-8.

2. Marszałek G, Majczak R. Polyethylene wax-preparation, modification and applications. Polimery. 2012;57:640-4.

3. Mishra N, Patra N, Pandey S, Salerno M, Sharon M, Sharon M. Taguchi method optimization of wax production from pyrolysis of waste polypropylene. J Therm Anal Calorim. 2014;117:885-92.

4. Sęp KM, Stolarski L. Modern technology of polyethylene production in Basell Orlen Polyolefins. Polimery. 2006;51:222-5.

5. Mngomezulu ME, Luyt AS, Krupa I. Structure and properties of phase-change materials based on high-density polyethylene, hard Fischer-Tropsch paraffin wax, and wood flour. Polym Compos. 2011;32:1155-63.

6. Mngomezulu ME, Luyt AS, Krupa I. Structure and properties of phase-change materials based on high-density polyethylene, soft Fischer-Tropsch paraffin wax. J Appl Polym Sci. 2010;118:1541-51.

7. Edwards Y, Tasdemir Y, Jsacsson U. Influence of commercial waxes on bitumen aging properties. Energy Fuels. 2005;19:2519-25.

8. Hadiya JP, Shukla AKN. Experimental thermal behavior response of paraffin wax as storage unit. J Therm Anal Calorim. 2016;124:1511-8.

9. Antosz A, Syrek H. Investigations on the production of wax microemulsions in a pressure reactor. Part II. Nafta-Gaz. 2014;70:520-7.

10. Jamal NA, Anuar H, Shamsul Bahri AR. The influence of EB irradiated treatment on enhancing barrier property and crystallization behavior of rubber- toughened nano-composites. J Nanotechnol. 2011. doi:10.1155/2011/683725. 